\title{
A Computationally Efficient 11 Band Non- Uniform Filter Bank for Hearing Aids Targeting Moderately Sloping Sensorineural Hearing Loss
}

\author{
Sajan P Philip, Sampath Palaniswami, Harikirubha Sivakumar
}

Bannari Amman Institute of Technology, Department of Electronics and Communication Engineering, Erode, Tamil Nadu, India

\begin{abstract}
A computationally efficient 11 band non-uniform filter bank addressing low or moderately sloping sensorineural hearing loss - the most common type of hearing problem- is proposed. This structure is suitable for low cost, small area implementations of hearing aids. The computational efficiency is achieved by adopting the Frequency Response Masking technique, which uses only two prototype filters with a total of 19 multipliers at $80 \mathrm{~dB}$ stopband attenuation for the design of entire non-uniform filter bank. The computational complexity analysis shows that the proposed method provides about a 70-90\% reduction in computational resources compared to non-FRM methods and about a 40-80\% reduction in computational resources compared to the other FRM methods. The audiogram matching performance analysis shows that the matching error of the proposed filter bank is negligible even without optimization. The delay performance of the filter bank is acceptable for both Closed Canal Fittings and Open Canal Fittings.
\end{abstract}

Keywords: filter bank; frequency response masking; interpolated FIR filter; hearing aid

\section{Računsko učinkovit 11 pasoven neenoten filter za slušno pomoč pri zmerni senzorno-nevralni izgubi sluha}

\begin{abstract}
Izvleček: Predlagan je računsko učinkovit 11 pasoven neenoten filter za slušno pomoč pri zmerni senzorno-nevralni izgubi sluha. Uporaben je pri ceneni in majhni implementaciji v slušne pripomočke. Računska učinkovitost je dosežena s tehniko maskiranja frekvenčnega odziva, ki uporablja le dva prototipna filtra z 19 množilniki pri 80 dB atenuaciji. Analiza je pokazala, d apredlagana metoda dosega 70 - 90\% zmanjšanje računskih operacij v primerjavi z ne-FRM metodami in 40-80\% izboljšanje v primerjavi z ostalimi FRM metodami. Analiza učinkovitosti avdiograma kaže zanemarljive napake tudi brez optimizacije. Zakasnitev filtra je sprejemljiva tako za ujemanje zaprtega kot odprtega kanala.
\end{abstract}

Ključne besede: filter; maskiranje frekvenčnega odziva; interpoliran FIR filter, slušna pomoč

*Corresponding Author's e-mail: sajanpphilip@bitsathy.ac.in

\section{Introduction}

The pioneering work by eminent researchers in multirate Digital Signal Processing (DSP), as summarized in $[1,2]$, had a tremendous impact on different fields of digital signal processing applications like Hearing Aids (HA). Digital HA, as an assistive listening device, has numerous advantages over its analog counterpart. Flexibility in frequency-dependent speech amplifica- tion, programmability, reconfigurability, noise suppression, feedback cancellation, and stability of the system against ageing are some of the critical advantages of digital HA. The significant concerns of HA design are group delay, power consumption, size of the device, and design complexity. 
Sensorineural Hearing Loss (SNHL) is the most common type of hearing loss that account for nearly $90 \%$ of the reported hearing loss. SNHL is an irrecoverable condition, and HAs are the most common type of treatment suggested for SNHL. Among the SNHL patients, most of the patients are reported with mild or moderate sloping audiograms representing the hearing loss towards higher frequencies. An example audiogram of a patient suffering from moderate sloping SNHL is shown in Figure 1. An audiogram is a graph used by HA experts to measure the softest sound a person can hear at different frequencies. The audiogram is recorded for both the ears. In figure 1, the ' $X$ ' marks represent the left ear, and ' $O$ ' marks represent the right ear.

The fundamental block diagram of a digital $\mathrm{HA}$ is shown in Figure 2. One of the critical parts of a digital HA is a Filter Bank (FB), which consumes almost half of the chip area and power compared to the other parts. The cost of implementing the filter bank with FIR filters that has a sharp transition width increases linearly with an increase in the order of the filter. Thus the fundamental philosophy of digital filter bank realization for audio application is to exploit the properties of FIR filters that result in efficient implementation. The reduction in computational resources of an HA has significant impacts on the overall size of the HAs. The size of HA is a crucial factor in In the Canal (ITC) and Completely in the Canal (CIC) HAs. The reduced computational requirement has multifold advantages like low power consumption, which is essential for battery operated low power HAs, and low-cost implementation.

An attempt to reduce the arithmetic operations in FIR filters, compared to direct form and linear phase implementation, by exploiting the redundancy of the filter coefficients, has resulted in a new class of filter implementation known as Interpolated FIR (IFIR) filter [3]. The main idea is to cascade an upsampler with an interpolator to create a sharp cut off filter using lower-order prototype filters. Another technique based on the IFIR to create sharp transition FIR filters known as Frequency Response Masking (FRM) is introduced in [4]. It is shown in [4] that proper 'masking and recombining' of the interpolated filter output, and its complementary output, can effectively reduce the cost of implementation of sharp filters at the expense of a specific delay added to the system. The same authors extended the work for audio equalization with a tree structure of Filters [5] to obtain reduced arithmetic operations for the realization of sub-filters. The advantage of FRM is that it will create filters with sparse coefficient values, which reduces the cost of implementation of the digital filter bank.

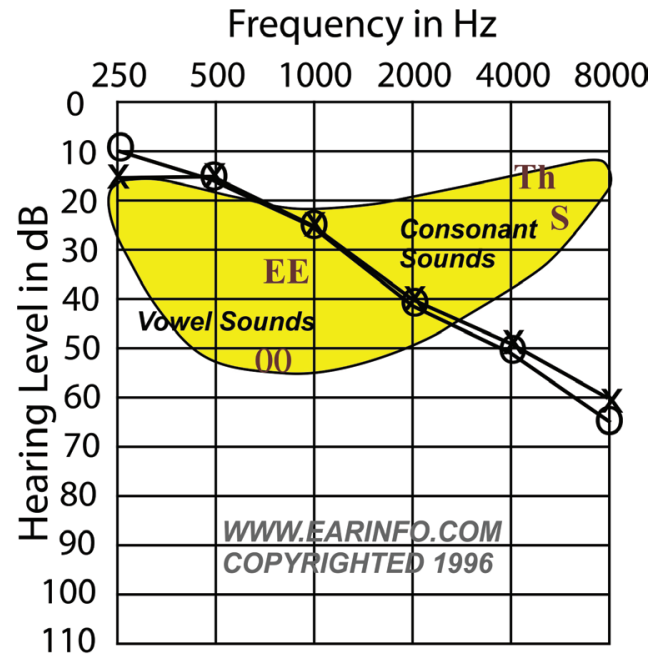

Figure 1: Sample Audiogram for Moderately sloping SNHL

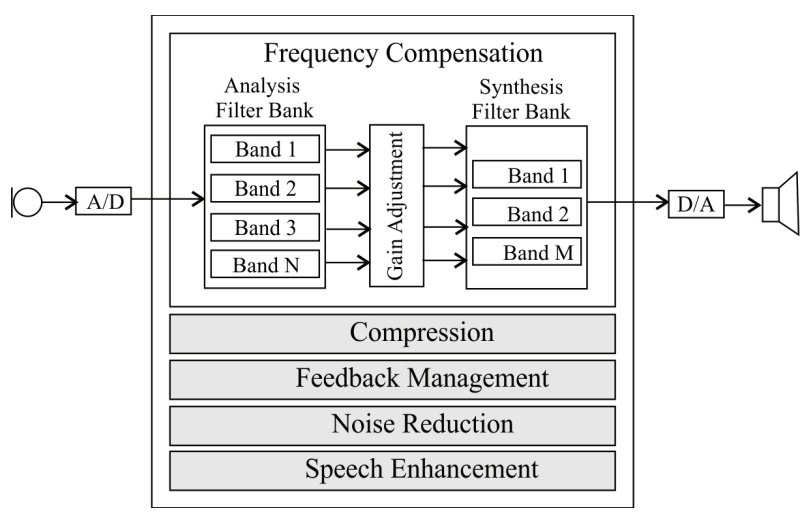

Figure 2: Block Diagram of a Digital Hearing Aid

Based on the above-discussed works, an eight-band an eight band IFIR filter bank for HAs has been proposed in [6]. The required frequency bands are created using half band complementary interpolated linear phase FIR filters. The frequency bands generated out of the structure was uniform in nature. One disadvantage of this method is that the delay of various frequency bands will vary, and it is required to use proper delay adjustments for a suitable group delay.

The idea of non-uniform filter banks is introduced in the papers [7-8] to match the non-uniform frequency characteristics of the human auditory system. They are based on FRM, half-band, and Complementary IFIR filter techniques. The above filter banks use only 2 Prototype Filters to realize the non-uniform filter bank. Improved version of the same idea using a different number of prototype filters for increased number of frequency bands are available in [9]. These implementations address the problems of hearing loss at high frequencies by allocating more bands at higher frequencies. A multibranch FRM scheme, which is an improved version of [9], 
is introduced in [10]. It has two or more than two Prototype filters, and an interpolated version of the same frequency masking filter is used to generate the required 16 bands NUFB. In this work, multiple prototype filters and multiplier sharing scheme is utilized to reduce the delay and complexity. However, uniform symmetric filter banks are used at the lower frequency and higher frequency region, which do not follow the octave band splitting scheme. The allocation of more bands at the higher frequency does not provide any added advantage but increases the complexity of the overall filter bank structure. Also, the multi prototype approach increases computational resources and the number of multipliers required to implement the design.

Reconfigurable FRM approaches to design NUFB are introduced in [11-13]. Combining different sub-band distribution schemes, these filter banks can provide a variety of band splitting choices at the expense of increased computational resources and delay. Various innovative ideas are presented in [12-13] to reduce the complexity of the design, which in turn resulted in increased group delay of the Filter Bank Structure. FRM approaches that can shape the frequency gain according to the NAL-NL1 prescription formula, at 1/3 octave frequencies provided by the ANSI S1.11 standards are introduced in [14-17]. The stringent constraints by the above specifications make the design of the filter bank very complicated. Realizations based on relaxed specifications of the above prescription formula can reduce the delay as explained in [15-16].

Other classes of Filter banks are Modulated filter banks and Farrow Structure filter banks [18-20]. They use various approaches of multirate signal processing and optimization techniques to obtain improved delay performance and matching error at the expense of complicated filter bank structure and computational resources. The reported results show that these designs require a vast number of multipliers and adders, which makes the filter bank structure power-hungry among all the other hardware components of the HAs.

The major contributions of this paper can be summarized as follows (i) Evolution of Interpolated Filter Bank for Implementation in HA is thoroughly reviewed (ii) Major design constraints for a filter bank in HA are deeply evaluated (iii) A computationally efficient filter bank structure for mild and moderately sloping SNHL audiograms is proposed (iv) Detailed design considerations of the proposed filter bank is explored and the same is explained with a design example (v) Experimental results of the proposed filter bank with other state-of-the-art filter bank architectures available in the literature are compared. The rest of the paper is organized as follows. In section 2 , significant design constraints for digital HA is briefly explained. These constraints are set by different results and conclusions from recent research in the field of Audiology. The structure and design of the proposed filter bank are detailed in Section 3. Experimental results are presented and thoroughly analyzed in section 4 . The results are compared with other works on filter bank design for HA reported in the literature and are discussed. The conclusion is drawn in section 5 .

\section{Design constraints of filter bank implementation in $\mathrm{HAs}$}

This section briefly explains the design constraints to be considered for a Filter bank used in a digital HA. The parameters described in this section need to be carefully analyzed by signal processing engineers and VLSI engineers for the efficient implementation of filter banks.

\subsection{Effect of group delay in HAs}

The usability of an HA is much dependent on the processing delay or group delay of the device. The two types of HA fittings usually employed in hearing-impaired patients are Open Hearing Aid Fitting (OHAF) and Closed Hearing Aid Fitting (CHAF). Examples of $\mathrm{OHAF}$ are Behind the Ear (BTE), and examples of CHAF are ITC and CIC type HAs. Research [21] shows that the delay difference of more than 5-10 ms can cause the 'Comb-Filtering effect' for the HA user. This effect is due to the superimposition of direct sound and amplified sound. The study conducted in [22-24] shows that a delay difference up to $30 \mathrm{~ms}$ is acceptable in the case of CHAF. The demand for CHAF has diminished in the past decade due to the 'Occlusion effect' usually found in such devices. Audiologists found that [25] occlusion effect is prominent if the delay is more than $10 \mathrm{~ms}$. Thus the delay difference of $10 \mathrm{~ms}$ between the actual sound and processed sound remained as an unofficial standard among $\mathrm{HA}$ engineers and audiologists. Active occlusion algorithms [26] can improve the situation in $\mathrm{CHAF}$ and increase the limit of tolerable delay in CHAF. A recent study in this area [27] shows that hearingimpaired users have significantly higher delay tolerance than ordinary people. Thus up to $20 \mathrm{~ms}$ delay is acceptable for hearing-impaired subjects in the case of CHAF. However, an increase in a processing delay of more than $30 \mathrm{~ms}$ can cause disruptions in audio-visual integration [28] and question the usability of the HA.

\subsection{Effect of number of frequency bands}

Increasing the number of bands for proper frequency compensation have a direct relationship with the processing complexity and delay of an HA. It is evident 
from the findings in [29] that for a moderate slope audiogram, four bands are adequate to provide flexible frequency shaping. However, audiograms with steep slope require more number of bands, and the frequency shaping accuracy increased significantly for seven bands. An extensive study conducted on 957 audiograms in [30] shows that the ideal number of bands required for HAs varies for an audiogram. However, a nine-band HA can accommodate the frequency shaping problem of most of the audiograms. According to the findings in [31], the number of bands required for steep audiograms lies between 9 to18. It is also shown in some studies [32] that the frequency shaping performance remains constant after eight bands for moderately sloping audiograms.

The filter bank in HA imitates the logarithmic perception of the basilar membrane in the ear and has narrow frequency resolution at lower frequencies compared to higher frequencies. Thus more number of bands need to be allocated at the lower frequencies. Increasing the number of bands at high frequencies does not have any proven advantage; instead, it increases the processing complexity and delay. These findings are explored in this work to design the proposed filter bank.

\subsection{Effect of Matching error}

In HA, hearing loss is compensated by adjusting the gain of the filter bank. The mismatch between prescribed gain and actual ear gain can cause discomfort to the HA user. The error mainly depends on the number of frequency bands and the flexibility of gain adjustment. The term 'matching error' is used to quantify the difference between the prescribed gain and gain adjustment curve provided by the filter bank. This is a measure used to analyze the performance of filter banks in HA. According to work reported in [33], the maximum matching error permitted for a filter bank is $\pm 5 \mathrm{~dB}$. Since there are chances of human error during $\mathrm{HA}$ fitting, it is always safe to limit the maximum permissible matching error as $\pm 3 \mathrm{~dB}$. The filter bank research articles explored in the introduction section [7-8, 12-13, 15-16, 19-20] targets to limit the matching error of the $\mathrm{HA}$ between $\pm 3 \mathrm{~dB}$ and $\pm 5 \mathrm{~dB}$.

\subsection{Computational constraints}

A significant factor affecting the customer satisfaction of HA is battery life. A study conducted in [34] shows that DSP processing hardware is responsible for about $70 \%$ of the energy consumption in a digital HA. Thus the critical component responsible for the power consumption among other DSP structures in HA is Filter Bank. Many of the work discussed earlier in this section $[10,12-16]$ have explored low power implementation strategies suitable for filter banks. Research shows that [35] HAs are more likely to be accepted if their benefit per unit of cost to the user is more.

Based on the analysis performed on the past research on VLSI signal processing [3-20] and audiology [21-37], the parameters that need to be considered for Filter Bank Design in Digital HA are summarized in Table 1.

\section{Proposed filter bank}

The proposed 11 bands filter bank is derived from a basic version of 12 bands filter bank which meticulously follows the 1/3 octave frequency splitting. The 11 band filter bank has a significant delay advantage over 12 bands basic version. In this section, the fundamental design of the 12 bands filter bank is presented and the design of the 11 band improved version is discussed. As shown in Figure 3, the proposed 12 bands filter bank is designed using a Double Prototype FRM scheme. This scheme is an advanced version of the IFIR scheme discussed in [3] and [4]. It has advantages over a multi prototype scheme [10] in saving the additional computations to design more number of sharp transition FIR filters.

So far, in the literature, we can see various filter bank schemes ranging from 8-17 bands. However, our proposed design can optimize the computational resources and keep the other parameters like delay and matching error within acceptable limits, making it suitable for low-cost implementations of HAs. Even the

Table 1: Summary of design constraints for filter bank design in HAs.

\begin{tabular}{|l|l|}
\multicolumn{1}{|c|}{ Parameter } & \multicolumn{1}{c|}{ Requirement } \\
\hline Audiogram Matching & $\begin{array}{l}\text { Capability to adjust the Mag- } \\
\text { nitude Response }\end{array}$ \\
\hline $\begin{array}{l}\text { Frequency Response } \\
\text { Characteristics }\end{array}$ & $\begin{array}{l}\text { Non-uniform suitable for the } \\
\text { human ear }\end{array}$ \\
\hline $\begin{array}{l}\text { Number of frequency } \\
\text { bands }\end{array}$ & $\begin{array}{l}\text { 4-8 for moderately sloping } \\
\text { Audiogram } \\
\text { 9-18 for steeply sloping } \\
\text { Audiogram }\end{array}$ \\
\hline Computational Cost & Less Number of Multipliers \\
\hline Group Delay & $\begin{array}{l}\text { Less than } 20 \text { ms for closed } \\
\text { fittings and Less than 10ms } \\
\text { for open fittings }\end{array}$ \\
\hline Power & $\begin{array}{l}\text { Suitable for Battery operated } \\
\text { working }\end{array}$ \\
\hline Area & $\begin{array}{l}\text { Suitable for ITC and CTC } \\
\text { hearing aid size }\end{array}$ \\
\hline Matching Error & Less than $\pm 5 \mathrm{~dB}$ \\
\hline
\end{tabular}




\begin{tabular}{|l|l|}
\hline $\begin{array}{l}\text { Stop Band Attenua- } \\
\text { tion }\end{array}$ & Greater than $60 \mathrm{~dB}$ \\
\hline Phase Response & Linear Phase \\
\hline Bandwidth & $\begin{array}{l}8 \mathrm{kHz} \text { for Normal HA } \\
10-12 \mathrm{kHz} \text { for Advanced high } \\
\text { Fidelity HA }\end{array}$ \\
\hline Aliasing & Inbuilt Cancellation \\
\hline
\end{tabular}

16 band filter bank designed in [10] can also be designed in this approach. However, our analysis shows that the additional bands realized in the high-frequency region do not have much effect on the audiogram matching; instead, it introduces compuataional overhead in the overall filter bank structure.

The selection of the sub-bands is made by keeping three objectives in mind. (i) To match the non-uniform characteristics of the human ear by providing $1 / 3$ octave splitting for the frequency region for satisfactory audiogram matching (ii) Reduce the unnecessary computations in the filter bank, especially in the high-frequencies and (iii) Keep the overall delay of the filter bank within the acceptable limit. The primary 12 band structure proposed is suitable for $\mathrm{CHAF}$ fittings in which up to $20 \mathrm{~ms}$ delay is acceptable. To make the structure ideal for $\mathrm{OHAF}$, we have proposed the second structure, which reduces the delay by removing a higher-order interpolation filter branch at the low-frequency region of the basic 12 band NUFB.

\subsection{Structure of the Proposed filter bank}

The structure of the Proposed filter bank is given in Figure 3 is motivated from $1 / 3$ octave splitting of frequencies. The cut-off frequencies of the proposed structure are determined based on different considerations like minimum matching error and computational resources. From the structure, it can be seen that only two Prototype Filters $\mathrm{H}_{1}(\mathrm{z}), \mathrm{H}_{2}(\mathrm{z})$, and their interpolated versions are utilized to obtain the required 12 bands. In this scheme, prototype filters have two roles (i) Band edge frequency shaping and (ii) Frequency masking. Hence this approach can be called a double prototype FRM scheme. In order to achieve high resolution at low frequencies, a sharp transition filter is required, and that leads to the use of a maximum interpolation factor of 12 in the proposed 12 band filter bank. The transfer functions and cut off frequencies of the 12 sub-filters used in the proposed structure is given in Table 2 .

An exciting finding from the analysis of low or moderately sloping audiograms is that the slope of the audiogram is less at low frequencies, and removal of the first band which uses an interpolation factor of 12 does not affect the matching error in a more significant manner. Thus we have also found that removing the first band from the structure will result in an 11 band structure, which can significantly improve the delay performance while keeping the matching error satisfactory in the low-frequency region $(250 \mathrm{~Hz}-500 \mathrm{~Hz})$. The 12 band structure can be used for audiograms with larger slope at $250 \mathrm{~Hz}$ region, and the 11 band structure can be used for zero slope audiograms at the $250 \mathrm{~Hz}$ region, respectively.

Generally, a single filter can be used to compensate for the frequency in the region from $4000 \mathrm{~Hz}$ to $8000 \mathrm{~Hz}$. However, this can lead to a significantly large matching error in the high-frequency region. Traditionally IFIR and FRM schemes adopt a symmetric structure in both low pass and high pass regions. The symmetric nature of the frequency bands is because the frequency bands required for high frequency regions are derived from the complementary filter approach [7]. However, we have found that providing four bands with a bandwidth of $1000 \mathrm{~Hz}$ in the region from $4000-8000 \mathrm{~Hz}$ is sufficient to provide adequate matching performance in the high-frequency region. The removal of unnecessary symmetrical branches at high frequencies reduced the number of adders in our implementation contrary to other implementations. The reduction of the total number of adders in the filter bank has a slight advantage of reduced computational complexity and significant advantage of reducing the adder dependent critical path delay in the output stage of the filter bank.

The graphical representations of the low pass filter responses $\left(A_{1}-A_{8}\right)$ and its corresponding complementary responses of the selected branches $\left(B_{1}-B_{4}\right)$ are shown in Figure 4. From the figure, it can be seen that the highfrequency regions require only four complementary filters with reduced interpolation factor of maximum 4. By performing suitable subtraction of the branches, we can obtain the sub-bands $\left(C_{1}-C_{8}\right.$ and $\left.D_{1}-D_{4}\right)$, as illustrated in Figure $4(\mathrm{~b})$. The 11 band filter bank will have the first low pass cut off frequency at $500 \mathrm{~Hz}$ instead of $250 \mathrm{~Hz}$ in 12 band filter bank, as shown in Figure 4 (c). Figure 4 (d) represents the formation of Sub bands in 11 band filter bank by suitable addition and subtraction of the filter responses. The cut-off frequencies of the Prototype filters $\mathrm{H}_{1}(\mathrm{z})$ and $\mathrm{H}_{2}(\mathrm{z})$ in both the structures are $4 \mathrm{kHz}$ and $3 \mathrm{kHz}$, respectively. These prototype filters can produce interpolated versions of the filter response with cut off frequencies $2 \mathrm{kHz}, 1.5 \mathrm{kHz}, 1 \mathrm{kHz}$, $750 \mathrm{~Hz}, 500 \mathrm{~Hz}$, and $250 \mathrm{~Hz}$.

\subsection{Design of the Proposed filter bank}

The implementation of the proposed filter bank is based on eight low pass filters denoted as $A_{i}(z)$ where $i=1$....8 and four high pass filters denoted as $B_{j}(z)$ where $j=1 . . .4$. The 12 sub bands are generated by the subtrac- 
tion of the high pass and low pass filters as shown in equation (1) and (2).

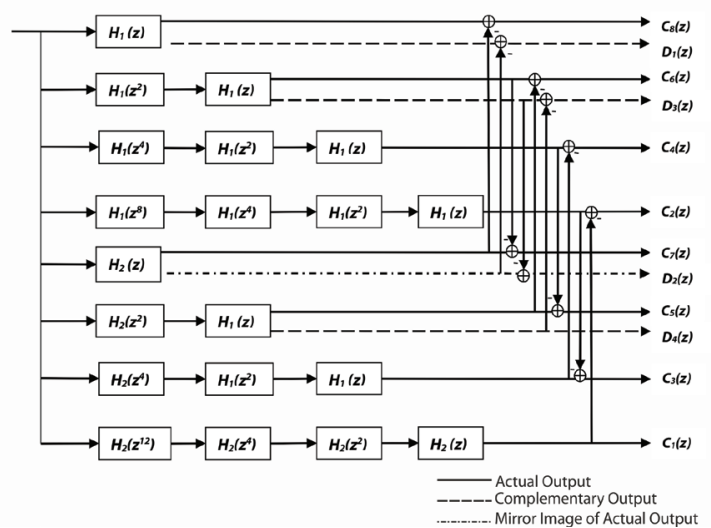

Figure 3: Structure of the proposed Filter Bank
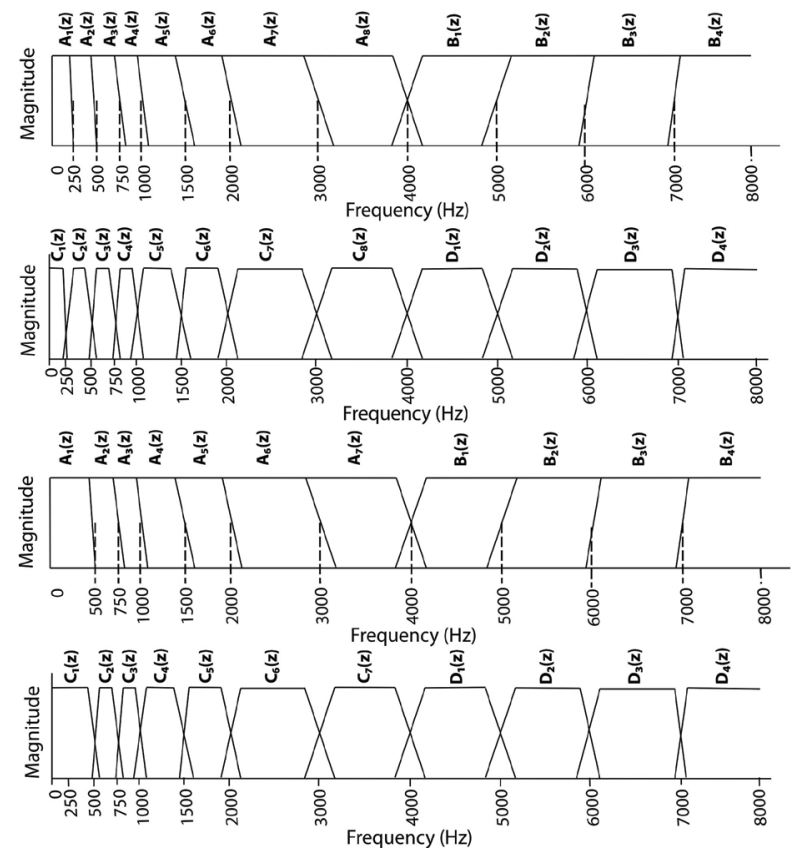

Figure 4: Magnitude response of LPFs and HPFs and Sub bands in Filter Bank (a) \& (b) 12 band (c) \& (d) 11 band

$$
\begin{gathered}
C_{i}(z)=\left\{\begin{array}{c}
A_{i}(z), i=1 \\
A_{i}(z)-A_{i-1}(z), i=2, \ldots, 8
\end{array}\right. \\
D_{j}(z)=\left\{\begin{array}{c}
B_{j}(z)-B_{j+1}(z), j=1, . ., 3 \\
B_{j}(z), j=4
\end{array}\right.
\end{gathered}
$$

Where $C_{i}(z)$ represents the sub bands in the frequency range $0 \mathrm{~Hz}-4 \mathrm{KHz}$ and $\mathrm{D}_{\mathrm{i}}(\mathrm{z})$ represents the sub bands in the frequency range $4 \mathrm{KHz}-8 \mathrm{KHz} . \mathrm{A}_{i}(\mathrm{z})$ and $\mathrm{B}_{i}(\mathrm{z})$ represents the low pass and high pass filter responses derived from the prototype filters $\mathrm{H}_{i}(\mathrm{z})$ and $\mathrm{H}_{2}(\mathrm{z})$.
Similarly, the general expressions to derive the bands in the 11 sub bands in the optimized filter bank is given by equation (3) and (4).

$$
\begin{aligned}
& C_{i}(z)=\left\{\begin{array}{c}
A_{i+1}(z), i=1 \\
A_{i+1}(z)-A_{i}(z), i=2, \ldots, 7
\end{array}\right. \\
& D_{j}(z)=\left\{\begin{array}{c}
B_{j}(z)-B_{j+1}(z), j=1, . ., 3 \\
B_{j}(z), j=4
\end{array}\right.
\end{aligned}
$$

The filter responses $\mathrm{H}_{1 c}(\mathrm{z})$ and $\mathrm{H}_{2 \mathrm{~h}}(\mathrm{z})$ required to generate the high pass filter bands as shown in Table 2 is derived from the equation given in (5) and (6).

$$
\begin{aligned}
& \mathrm{H}_{1 \mathrm{c}}(\mathrm{z})=\mathrm{z}^{\frac{\mathrm{N}-1}{2}}-\mathrm{H}_{1}(\mathrm{z}) \\
& \mathrm{H}_{2 \mathrm{~h}}(\mathrm{z})=\mathrm{H}_{2}(-\mathrm{z})
\end{aligned}
$$

It can be seen from the analysis that the delay performance of the filter bank directly depends on the sampling frequency of the input signals. Suppose we want to design a 12 band non-uniform filter bank whose frequency range is from $\mathrm{OHz}$ to $8 \mathrm{kHz}$. The sampling frequency should be greater than or equal to $16 \mathrm{kHz}$ $\left(2 f_{m}\right)$ in order to satisfy the Nyquist sampling criteria. However, modern HAs are using other sampling rates like $20 \mathrm{kHz}$ and $24 \mathrm{kHz}$ also for the high fidelity listening experience.

The design parameters that need to be determined for the required audiogram matching include gains for each sub-band, transition bandwidth for each prototype filters, and the group delay of the overall filter bank. The gain of each sub-band depends on the type of audiogram to be matched. The proposed filter bank is designed by keeping low or moderately sloping SNHL audiograms as targetted audiograms. In order to achieve high resolution in the low-frequency region, sharp transition width filters are required and which significantly increases the order of the filter bank. In our approach, the interpolation and frequency masking is used to overcome this limitation and to produce sharp filters. It is a known fact that interpolation factor $M$ of a filter introduces $M$ replicas of the prototype filter with sharp transition bandwidth [1-2,5]. It is required to mask the unwanted replicas due to interpolation, and that is the reason for using Prototype filter for both frequnecy band creation and masking. 
Table 2: Cut off frequencies and Transfer functions of sub bands in the filter bank

\begin{tabular}{|c|c|l|}
\hline \multicolumn{1}{|c|}{ Band } & $\begin{array}{c}\text { Frequency } \\
\text { Range }(\mathrm{Hz})\end{array}$ & \multicolumn{1}{|c|}{ Transfer Function } \\
\hline A1 & $0-250$ & $\mathrm{H}_{2}\left(\mathrm{z}^{12}\right) \mathrm{H}_{2}\left(\mathrm{z}^{4}\right) \mathrm{H}_{2}\left(\mathrm{z}^{2}\right) \mathrm{H}_{2}(\mathrm{z})$ \\
\hline A2 & $0-500$ & $\mathrm{H}_{1}\left(\mathrm{z}^{8}\right) \mathrm{H}_{1}\left(\mathrm{z}^{4}\right) \mathrm{H}_{1}\left(\mathrm{z}^{2}\right) \mathrm{H}_{1}(\mathrm{z})$ \\
\hline A3 & $0-750$ & $\mathrm{H}_{2}\left(\mathrm{z}^{4}\right) \mathrm{H}_{1}\left(\mathrm{z}^{2}\right) \mathrm{H}_{1}(\mathrm{z})$ \\
\hline A4 & $0-1000$ & $\mathrm{H}_{1}\left(\mathrm{z}^{4}\right) \mathrm{H}_{1}\left(\mathrm{z}^{2}\right) \mathrm{H}_{1}(\mathrm{z})$ \\
\hline A5 & $0-1500$ & $\mathrm{H}_{2}\left(\mathrm{z}^{2}\right) \mathrm{H}_{1}(\mathrm{z})$ \\
\hline A6 & $0-2000$ & $\mathrm{H}_{1}\left(\mathrm{z}^{2}\right) \mathrm{H}_{1}(\mathrm{z})$ \\
\hline A7 & $0-3000$ & $\mathrm{H}_{2}(\mathrm{z})$ \\
\hline A8 & $0-4000$ & $\mathrm{H}_{1}(\mathrm{z})$ \\
\hline B1 & $4000-8000$ & $\mathrm{H}_{1 c}(\mathrm{z})$ \\
\hline B2 & $5000-8000$ & $\mathrm{H}_{2 \mathrm{~h}}(\mathrm{z})$ \\
\hline B3 & $6000-8000$ & $\mathrm{H}_{1}\left(\mathrm{z}^{2}\right) \mathrm{H}_{1} \mathrm{c}(\mathrm{z})$ \\
\hline B4 & $7000-8000$ & $\mathrm{H}_{1}\left(\mathrm{z}^{4}\right) \mathrm{H}_{1}\left(\mathrm{z}^{2}\right) \mathrm{H}_{1} \mathrm{c}(\mathrm{z})$ \\
\hline
\end{tabular}

A. Gain Adjustment of Sub bands and Calculation of Matching Error

The gain adjustments for different filters in the filter bank are performed as given below.

Let

$$
\begin{aligned}
& \mathrm{P}=\left[\mathrm{p}_{1}, \mathrm{p}_{2}, \mathrm{p}_{3}, \ldots, \mathrm{p}_{\mathrm{N}}\right]^{\mathrm{T}} \\
& \mathrm{M}=\left[\mathrm{C}_{1}, \mathrm{C}_{2}, \ldots, \mathrm{C}_{8}, \mathrm{D}_{1}, \ldots, \mathrm{D}_{4}\right]
\end{aligned}
$$

Here, $\mathrm{P}$ is the sampled audiogram with $\mathrm{N}$ data points. The value of $i_{\text {th }}$ sample of $P$ is $p_{i}$. Similary $C_{k}$ is the sampled magnitude response of the filters in the frequency region between $\mathrm{OHz}$ and $4 \mathrm{KHz}$ and $\mathrm{D}_{\mathrm{k}}$ is the sampled magnitude response of the filters in the frequency region between $4 \mathrm{KHz}$ and $8 \mathrm{KHz}$.

Assume that the gain of each band is given as $g_{i}(i=1,2$, $\ldots, 12$ ) and $C_{k}$ is the magnitude response of the kth sub band $(k=1,2, \ldots, 8)$ in logarithmic scale. $D_{k}$ is the magnitude response of the $8+k_{\text {th }}$ sub band $(k=1,2, \ldots, 4)$ in logarithmic scale as showin in equation (9) and (10)

$$
\begin{aligned}
& \mathrm{G}=\left[\mathrm{g}_{1}, \mathrm{~g}_{2}, \mathrm{~g}_{3}, \ldots, \mathrm{g}_{12}\right]^{\mathrm{T}} \\
& \mathrm{C}_{\mathrm{k}}=\left[\mathrm{c}_{\mathrm{k}, 1}, \mathrm{c}_{\mathrm{k}, 2}, \mathrm{c}_{\mathrm{k}, 3}, \ldots, \mathrm{c}_{\mathrm{k}, \mathrm{N}}\right], \mathrm{k}=1,2, \ldots, 8 \\
& \mathrm{D}_{\mathrm{k}}=\left[\mathrm{d}_{\mathrm{k}, 1}, \mathrm{~d}_{\mathrm{k}, 2}, \mathrm{~d}_{\mathrm{k}, 3}, \ldots, \mathrm{d}_{\mathrm{k}, \mathrm{N}}\right], \mathrm{k}=1,2, \ldots, 4
\end{aligned}
$$

The matching curve can be obtained by summing the magnitude response of all the filters in the filter bank after performing the required gain adjustment suitable for the audiogram. The matching curve, $S$ is given by,

$$
\mathrm{S}=\sum_{\mathrm{i}=1}^{8} \mathrm{C}_{\mathrm{i}} \mathrm{g}_{\mathrm{i}}+\sum_{\mathrm{i}=1}^{4} \mathrm{D}_{\mathrm{i}} \mathrm{g}_{8+\mathrm{i}}
$$

The matching error is obtained by finding the difference between the audiogram and the matching curve.
The matching error, $\mathrm{E}$ is given by,

$$
\mathrm{E}=\mathrm{P}-\mathrm{S}
$$

The maximum absolute error in $\mathrm{dB}$ is given by

$$
\mathrm{E}_{\max }=\max |\mathrm{P}-\mathrm{S}|
$$

Different optimization schemes can further optimize the matching error. In [10] minimax optimization scheme applied and in [8] minimum least square error scheme is applied to optimize the matching error. Since our matching error results fall under an accepted matching error limit, we have presented our results without optimization. In all the works reported, on average, the optimization can reduce the matching error by about $40-50 \%$. Hence it is evident that optimization can achieve better matching in the proposed design also, which makes it suitable for computationally efficient low-cost implementation with a better matching result.

B. Calculation of Transition Bandwidth of the Filter Responses

In order to obtain proper passband for each subband, the stopband edge of $A_{i-1}$ must be smaller than the passband edge of $A_{i}$ (i.e the value of $x$ should be less than the value of $y$ as shown in the below Figure 5). To satisfy the above condition, the transition bandwidth of both the prototype filters is selected to be equal. To determine the required transition width for the proposed filter bank structure, the filterbank is designed for different transition bandwidths varying from $0.3 \mathrm{kHz}$ to $1.5 \mathrm{kHz}$ and corresponding matching errors are noted. A table showing the effect of Transition width on the Maximum Matching Error (MME) of the Audiogram is given in Table 3. The Transition width and the maximum matching error without optimization is presented.

From Table 3, it is observed that the minimum matching error is obtained when the transition bandwidth is $1 \mathrm{kHz}$. The second minimum matching error occurs at $1.2 \mathrm{kHz}$. Also, it is observed that the matching error decreases with the increase in the transition bandwidth up to $1 \mathrm{kHz}$. Further increase in transition bandwidth worsens the matching error due to overlap among different bands, especially in the low frequency where the sub-bands are narrow. From the analysis, $1 \mathrm{KHz}$ is

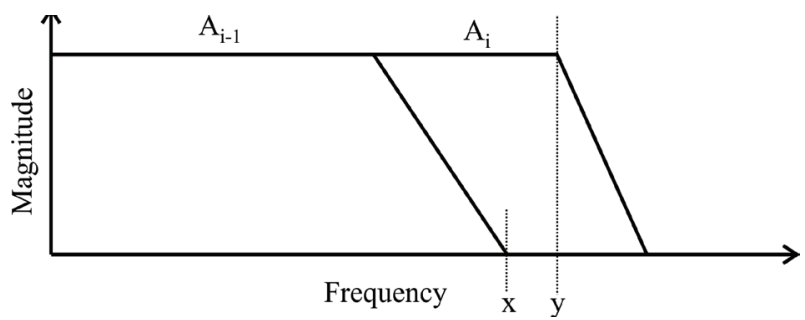

Figure 5: Method of generating the Sub bands 
selected as the best suitable transition width for minimum matching error. However, it can be shown that the computational resources can be reduced if we select the transition bandwidth as $1.2 \mathrm{kHz}$. This is because, from Table 3, it can be seen that the number of non-zero coefficients required to implement the two prototype filters is 19 for transition width $1 \mathrm{kHz}$, and that is 14 for transition width $1.2 \mathrm{kHz}$.

These 19 non zero coefficients are responsible for the multiplications in the filter bank, and it also affects the group delay of the filter bank. However, the transition width of $0.8 \mathrm{kHz}$ increases the computational requirements by $50 \%$, and the transition width of $1.2 \mathrm{kHz}$ decreases the computational requirement by $25 \%$.

\section{Delay Analysis of the Filter Bank}

The delay of the proposed filter bank $T_{d}$ can be calculated using the following equation.

$\mathrm{T}_{\mathrm{d}}=\mathrm{T}_{\mathrm{b}}+\mathrm{T}_{\mathrm{m}}$

Where $T_{b}$ is the delay of generating multiple bands by interpolation and $T_{m}$ is the delay of masking filters, which is used to separate the required low pass or high pass version from the multiple bands.

For a linear phase interpolated filter $\mathrm{H}(\mathrm{zM})$, its group delay is given by

$$
\mathrm{t}=\left[\frac{\mathrm{L}-1}{2}\right] \frac{\mathrm{M}}{\mathrm{f}_{\mathrm{s}}}
$$

Where, $L$ is the length of the prototype filter, $M$ is the interpolation factor and $\mathrm{fs}$ is the sampling frequency.

In the proposed 12 band filter bank structure, the maximum delay is found at the lowermost branch, which is used for generating the narrow band filter $C_{1}(z)$. Since the entire branch is derived from a single prototype filter, the total delay is given as

$\mathrm{t}_{\text {tot }}=\left[\frac{\mathrm{L}-1}{2}\right] \frac{\left(\mathrm{M}_{1}+\mathrm{M}_{2}+\mathrm{M}_{3}+\mathrm{M}_{4}\right)}{\mathrm{f}_{\mathrm{s}}}$

Where $M_{1}, M_{2}, M_{3}$ and $M_{4}$ are the interpolation factors of $\mathrm{H}_{2}(\mathrm{z} 12), \mathrm{H}_{2}(\mathrm{z} 4), \mathrm{H}_{2}(\mathrm{z} 2)$, and $\mathrm{H}_{2}(\mathrm{z})$, respectively, $\mathrm{L}$ is the length of the prototype filter $\mathrm{H}_{2}(\mathrm{z})$. By substituting the values for $M_{1}, M_{2}, M_{3}$ and $M_{4}$ we get

For 12 Band filter bank,

$\mathrm{t}_{\text {tot }}=\left[\frac{\mathrm{L}-1}{2}\right] \frac{(12+4+2+1)}{\mathrm{f}_{\mathrm{s}}}=\left[\frac{\mathrm{L}-1}{2}\right] \frac{19}{\mathrm{f}_{\mathrm{s}}}$

For 11 Band filter bank,

$\mathrm{t}_{\text {tot }}=\left[\frac{\mathrm{L}-1}{2}\right] \frac{(8+4+2+1)}{\mathrm{f}_{\mathrm{s}}}=\left[\frac{\mathrm{L}-1}{2}\right] \frac{15}{\mathrm{f}_{\mathrm{s}}}$
Therefore, the delay of the filter bank for $1 \mathrm{kHz}$ transition bandwidth $(\mathrm{L}=27)$ is $\frac{195}{f_{s}}$ and the delay of the filter bank for $1.2 \mathrm{kHz}$ transition bandwidth $(\mathrm{L}=21)$ is $\frac{150}{f_{s}}$.

Table 4 summarizing the delay of the proposed 12 band and 11 band filter banks for different sampling frequencies and transition widths.

\section{Design Example}

In our proposed design, we are using only two prototype filters. The design of an FRM filter bank with more number of prototype filters can reduce the processing delay at the cost of increased computational resources. A single prototype filter may add a limitation to the design as it is required to provide frequency band shaping and masking. Hence it is required to select the cut off frequencies of the filters in such a way that it can be used as both band shaping filter and masking filter.

Table 3: Effect of Transition width on Maximum Matching Error (MME)

\begin{tabular}{|c|c|c|c|c|c|}
\hline \multirow{2}{*}{ 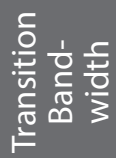 } & \multirow{2}{*}{ 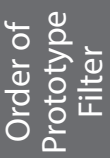 } & \multicolumn{3}{|c|}{ Unique Coefficients } & \multirow{2}{*}{ 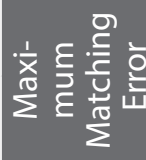 } \\
\hline & & $\mathrm{H}_{1}(\mathrm{z})$ & $\mathrm{H}_{2}(\mathrm{z})$ & Total & \\
\hline $0.3 \mathrm{kHz}$ & 80 & 20 & 38 & 58 & 2.0362 \\
\hline $0.5 \mathrm{kHz}$ & 52 & 14 & 24 & 38 & 1.7346 \\
\hline $0.8 \mathrm{kHz}$ & 38 & 10 & 18 & 28 & 1.3527 \\
\hline $1 \mathrm{kHz}$ & 26 & 7 & 12 & 19 & 1.1107 \\
\hline $1.2 \mathrm{kHz}$ & 20 & 5 & 9 & 14 & 1.3756 \\
\hline $1.5 \mathrm{kHz}$ & 13 & 4 & 6 & 10 & 1.5274 \\
\hline
\end{tabular}

Table 4: Delay of Proposed Filter Banks for different sampling frequencies.

\begin{tabular}{c|c|c|c|c|}
\multirow{2}{*}{$\begin{array}{c}\text { Sampling } \\
\text { Frequency }\end{array}$} & \multicolumn{3}{|c|}{$\begin{array}{c}\text { Delay of } 12 \text { Band } \\
\text { Filter Bank (ms) }\end{array}$} & $\begin{array}{c}\text { Delay of } 11 \text { Band } \\
\text { Filter Bank (ms) }\end{array}$ \\
\cline { 2 - 5 } & \multicolumn{4}{|c|}{ Transition widths } \\
\cline { 2 - 5 } & $1 \mathrm{kHz}$ & $1.2 \mathrm{kHz}$ & $1 \mathrm{kHz}$ & $1.2 \mathrm{kHz}$ \\
\hline $16 \mathrm{kHz}$ & 15.4 & 11.9 & 12.9 & 9.4 \\
\hline $20 \mathrm{kHz}$ & 12.35 & 9.5 & 9.75 & 7.5 \\
\hline $24 \mathrm{kHz}$ & 10.3 & 7.9 & 8.12 & 6.25 \\
\hline
\end{tabular}

Now, different low pass filter bands are designed using interpolation of prototype filters. High pass filters are derived from the complementary approach and half band approach are used to reduce the coefficients. Appropriate filter bands are used to mask the filter responses. The audiogram matching is performed with different transition widths. A base transition width is selected which reduces the matching error. Different optimization techniques can be used to obtain better 
matching results. Commonly used optimization methods are min-max optimization [10] and minimum leastsquare optimization [8]. The optimization process needs to be incorporated into the HA fitting software, which makes the overall HA fitting process complex and costlier. Hence we have presented our results without optimization and are comparable with the results obtained through various optimization schemes.

Delay of the filter bank is depending on the order of the prototype filter and the maximum interpolation factor used in a particular path. Decreasing the order of the filter can improve the delay, but that worsens the matching performance of the filter bank. The tradeoff between matching error and delay is analyzed, and the order of the Prototype filter is fixed. Once the bands of the filter banks are obtained, it is required to individually adjust the gain for each band based on the audiogram.

\section{Experimental results and discussion}

\subsection{Selection of audiograms}

In order to verify the effectiveness of the proposed design, we have examined the performance of the proposed filter bank against four standard audiograms of SNHL patients as given in Figure 6. These Audiograms are taken from Independent Hearing Aid Information, a public service by Hearing alliance of America [38]. All the works compared in this work have used the same audiograms to compare the efficiency of their design. Out of the eight different audiograms available, four are considered for evaluation. These four audiograms are selected based on the criteria of the proposed design, that is, the proposed filter bank design is for mild or moderate sloping Audiograms. Out of the four, two audiograms representing mild sloping and the other two represent moderate sloping audiograms. Since the remaining four audiograms available in the database are notched audiograms with substantial variation in middle frequencies representing rare cases of hearing loss, they are not considered for evaluation in this work. A brief description of the audiograms considered for evaluation is given below.

The audiogram represented as Type 1 is the most common type of audiogram found in aged people. This audiogram represents typical SNHL Hearing loss. In this hearing loss, the HA should leave the low-frequency region untouched and provide mild and moderate amplifications to the sound at middle and high frequencies. The audiogram represented as Type 2 is another common audiogram but represents mild to moderate hearing loss in the low-frequency region. We can see that the hearing loss in the high-frequency region is minimal. The effect of such a hearing loss is the loss of loudness, and the patient may be unaware of some natural sounds or sounds in various conversations. Type 3 audiogram is commonly found in people working in noisy environments. Like in Type 1, in the low-frequency region, it is required to perform only very low amplification. Type 4 audiogram represents total hearing loss at high frequencies. People with this class audiograms have moderate hearing loss at low frequency and high hearing loss at middle frequency. Since there is a total loss at high frequency, the hearing range of the patient will be minimal.

\subsection{Simulation results}

The simulation of the proposed filter bank and matching of the audiograms are performed in the Matlab R2017b environment. The Low pass and high pass versions of the sub-band filters are designed, as explained in the previous section. The individual sub-bands are separated using masking, and the corresponding 12 band and 11 band filter banks are generated. The transition bands of the filters are adjusted in such a way that minimum matching error will be obtained for Type 1 Audiogram. Once the Filter banks are designed, Gain matching is performed for each Audiograms from Type 1 to Type 4 .

The Low Pass and High pass versions of the Filters for 12 bands and 11 band filter banks are given in Figure $7(a)$ and $7(b)$. These subfilters are subtracted in the proper order to generate the required filter bank structure as shown in Figure 7(c) and 7(d)The matching curve is plotted against the audiograms after the gain adjustment to calculate the matching error. From the matching Curve, Matching error is plotted to calculate the Maximum Matching Error (MME) for each audiogram. The Matching Curve and Matching error corresponding to each audiogram are given in Figure 8. It can be seen from the simulation that the matching performance of the proposed filter bank is reasonable for all the audiograms. The audiogram matching is performed and presented without optimization. From the matching curves, it can be seen that both the 11 band and 12 band filter banks follow the same matching curve except at the beginning of the audiogram. We have also evaluated the performance of 10 band filter bank, that can be achieved by removing one more lowfrequency band in the region $500 \mathrm{~Hz}-750 \mathrm{~Hz}$. However, it does not have any computational or delay improvement; rather, it increases the matching error. Thus we have obtained the optimum number of bands that can give better results in this approach as 11 bands.

It can be seen from the matching curve that this approach flexibly following the audiogram of the hearing impaired person of Type 1 and Type 2 audiogram, which is the most common type of hearing loss, ac- 
counts for a major portion of hearing loss in the world. However, the matching error slightly increased for Type 3 and Type 4 audiograms due to the increased slope in the lower and middle frequencies. The MME is largely contributed by the low-frequency region and middlefrequency region, and the high-frequency region frequency region has less impact on the MME. The best matching is achieved for Type 2 audiogram followed by Type 1, Type 3, and Type 4.

All the matching error falls under the acceptable limit of $\pm 5 \mathrm{~dB}$, which indicates that the proposed filter bank structure is suitable for sloping audiograms. However, the proposed scheme is not susceptible to large slope variation in the middle-frequency region. This is due to the fact that FRM scheme uses larger bands in the middle frequency region compared to the lower and higher frequencies. The matching performance can be further improved by allocating more number of bands in the middle frequency region, but it will eventually result in an increased number of multipliers and increased group delay of the HA.

\subsection{Performance comparison and discussion}

A detailed comparison of the proposed filter banks with existing filter banks is given in Table 5. The comparison is made with both FRM based and non-FRM based techniques. From Table 5, it is evident that the proposed filter banks use less computational resources compared to the other techniques. The MME of the proposed filter bank is also superior to the other techniques except [15]. However, comparing the computational resources, the implementation of [15] requires more number of multipliers and the delay is also comparatively high. It is to be noted that the MME of [8] and [10] given in the table are optimized results. Optimization of the proposed filter bank also can provide comparable results with [8] and [10]. However, it is not included in the table as it is not a usual practice in $\mathrm{HA}$ fitting process. All the reported works except [8] provide acceptable matching performance for all the audiograms. However, the matching performance of [8] for Type 3 and Type 4 audiograms is not acceptable for real time implementations of HAs.

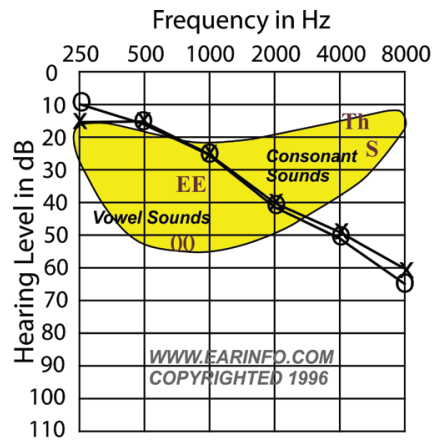

(a)

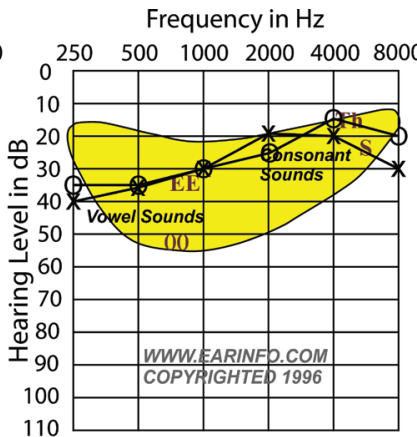

(b)

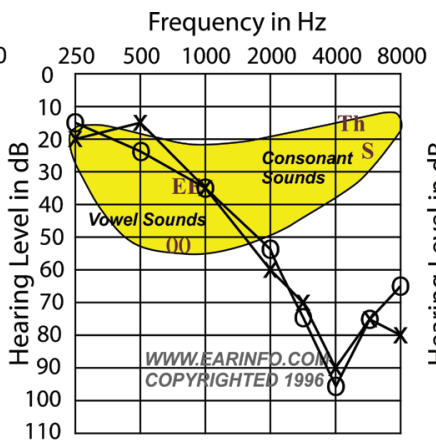

(c)

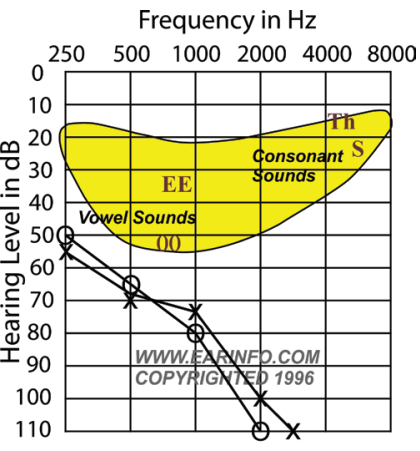

(d)

Figure 6: (a) Type 1 (b) Type 2 (c) Type 3 (d) Type 4 Audiograms

Table 5: The Comparison of non-uniform Filter Banks designed for Hearing Aids

\begin{tabular}{|c|c|c|c|c|c|c|c|c|c|c|}
\hline \multirow{2}{*}{ Filter bank } & \multirow{2}{*}{ 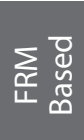 } & \multicolumn{4}{|c|}{$\begin{array}{l}\text { Maximum Matching Error (MME) } \\
\text { for Different Audiograms (in dB) }\end{array}$} & \multicolumn{2}{|c|}{$\begin{array}{l}\text { Computational Re- } \\
\text { source Requirement }\end{array}$} & \multicolumn{3}{|c|}{ Delay (ms) } \\
\hline & & Type 1 & Type 2 & Type 3 & Type 4 & \#Multipliers & \#Adders & $f_{s}=16 \mathrm{kHz}$ & $f_{s}=20 k H z$ & $f_{s}=24 k H z$ \\
\hline Cosine Modulated [18] & $\mathrm{N}$ & 2.49 & 2.19 & - & - & 192 & 384 & - & - & - \\
\hline Reconfig. 1 [12] & $\mathrm{Y}$ & - & - & - & - & 90 & 190 & 29 & 23.2 & 19.33 \\
\hline Reconfig. 2 [13] & $\mathrm{Y}$ & - & - & - & - & 76 & 170 & 12.1 & 9.68 & 8.07 \\
\hline Farrow 1 [19] & $\mathrm{N}$ & 2.45 & 1.67 & - & - & 216 & 432 & 1.1 & 0.88 & 0.73 \\
\hline Farrow 2 [20] & $\mathrm{N}$ & 2.60 & 1.51 & 2.96 & - & 138 & 276 & 1.3 & 1.04 & 0.87 \\
\hline QANSI [15] & $\mathrm{N}$ & - & 0.1 & 0.6 & - & 226 & 452 & 15 & 12 & 10 \\
\hline QANSI 1 [16] & $\mathrm{N}$ & 4.28 & - & - & - & 64 & 128 & 16.88 & 13.5 & 11.25 \\
\hline QANSI 2 [16] & $\mathrm{N}$ & 1.18 & - & - & - & 72 & 144 & 18.81 & 15.07 & 12.56 \\
\hline $\begin{array}{l}\text { FRM } 8 \text { band }[8] \\
\text { (Optimized) }\end{array}$ & Y & 0.83 & 2.11 & 14.13 & 9.64 & 18 & 36 & 12.8 & 10.24 & 8.533 \\
\hline $\begin{array}{l}\text { FRM } 16 \text { band [10] } \\
\text { (Optimized) }\end{array}$ & Y & 0.42 & 0.27 & 4.33 & 1.63 & 33 & 64 & 6 & 4.8 & 4 \\
\hline Proposed 12 band & $\mathrm{Y}$ & 1.11 & 0.74 & 3.26 & 2.98 & 19 & 38 & 15.4 & 12.35 & 10.3 \\
\hline Proposed 11 band & $Y$ & 1.11 & 0.74 & 3.26 & 3.23 & 19 & 38 & 12.9 & 9.75 & 8.12 \\
\hline
\end{tabular}




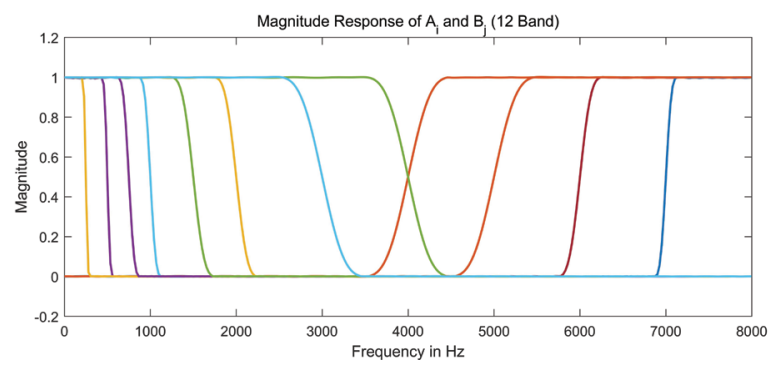

(a)

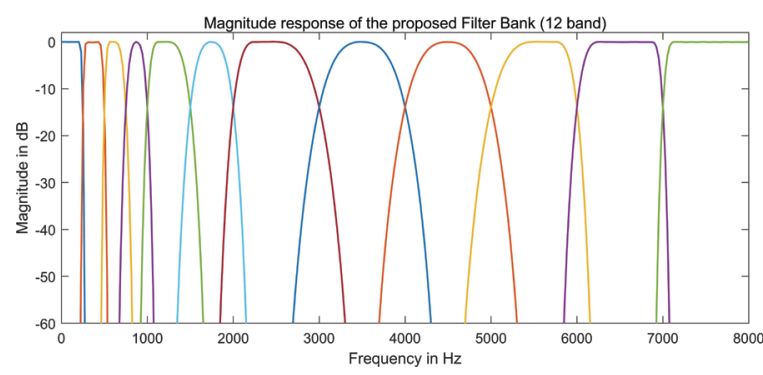

(b)

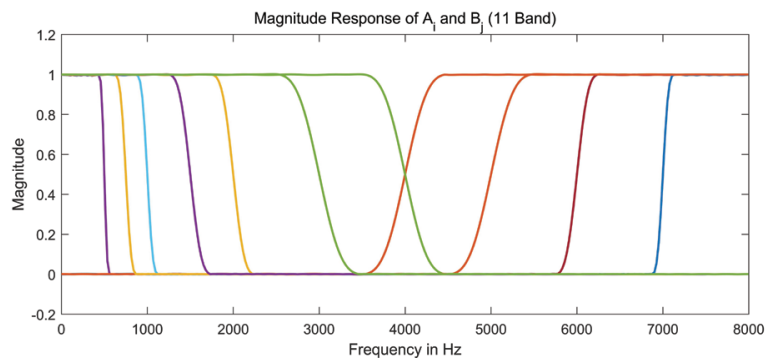

(c)

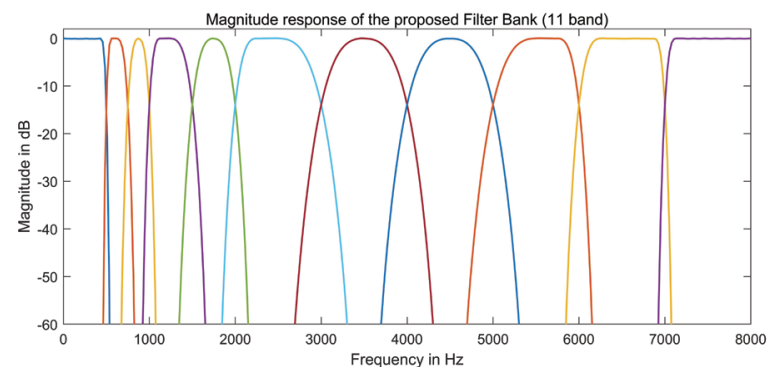

(d)

Figure 7: Simulation results of LPFs and HPFs in Filter banks \& Sub bands in Filter banks (a) \& (b) 12 Band (c) $\&$ (d) 11 band

The delay performance of the proposed filter bank is within the acceptable limit for both OHAF and CHAF. The delay performance of [10] is superior to the proposed method as it is implemented using 3 Prototype filters. Implementation of 3 prototype filters requires more number of multipliers compared to our approach. The results shown in [10] claims that the matching per- formance is achieved using only 33 multipliers, but our estimation shows that this number is very less for the reported matching result.

From the comparison table, it is clear that the FRM based methods $[8,10]$ have the advantage of reduced computational complexity but has a higher delay. Among the various work reported, Cosine Modulated Filter Bank (CMFB) approach [18] provides the lowest delay filter bank. This is because CMFB filter banks do not use the concepts of interpolation and masking approach.

However, the large number of multipliers and adders makes it significant in the chip area and consumes huger battery power. Reconfigurable filter banks [12-14] offer flexibility in a different type of audiogram matching, especially audiograms with notching in the middle frequency region. However, in this kind of filter banks, the computational complexity is enormous.

Among the filter banks considered for comparison, QANSI filter provides the best audiogram matching performance. Even though the QANSI approaches [1517] follow the standard prescription formula, the significant computational resources, increased delay, and tedious design process makes it inferior to FRM methods. Among the FRM methods, the proposed structure has more computational efficiency with better matching performance. The delay is kept within the acceptable limits, and the performance of the 11 band filter bank is promising to be used in low-cost implementations of HAs used in OHAF and CHAF. The MME of Type 1 audiogram for the proposed filter bank structure is the lowest among all the reported works. The MME of Type 2 is superior to all the other works reported except [15], Type 3 and Type 4 audiograms also provide comparable results with other filter banks.

The main attraction of the proposed filter bank structure is the lowest computational complexity among all the other works reported. It can be seen from the table that the proposed method requires only 19 multipliers to implement 12 bands and 11 bands structures. If we consider the 11 band filter bank for actual implementation this is about an average $70-90 \%$ reduction in the number of multipliers and adders required for the filter bank implementation compared to the non FRM methods. Among the FRM methods, it can be seen that using only one extra multiplier, the proposed filter bank generates three additional frequency bands in the low-frequency region compared to [8]. These extra bands have apparent advantages of matching performance, as seen from the table. The number of multipliers required per band for [8] is 2.25 , and that of the proposed method is 1.72 . Also, the multipliers re- 
quired per band for [10] are 2.06. The results show that the proposed method achieves comparable matching performance with [10] using the reduced number of bands. The adders are also reduced significantly compared to the other FRM methods. This can reduce the adder dependent delay in the actual implementation. The delay of the proposed 12 band filter bank is acceptable but larger compared to the FRM methods. However, the delay performance of the proposed 11 band

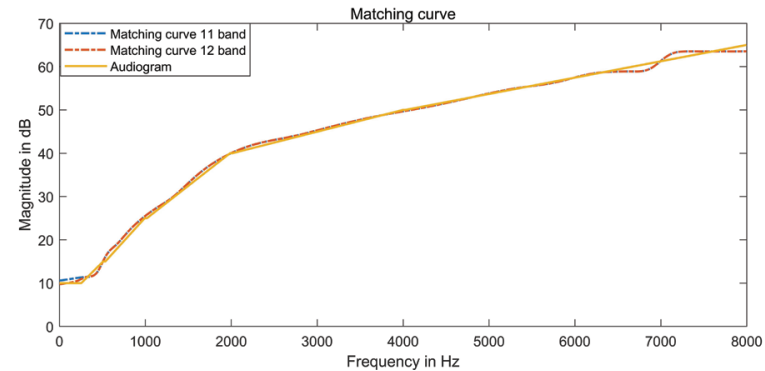

(a)

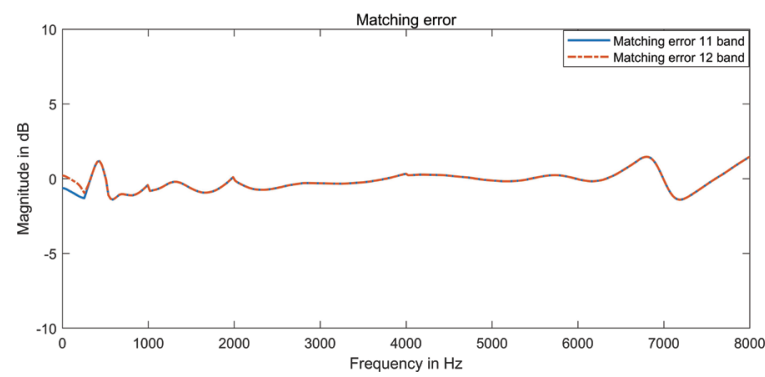

(b)

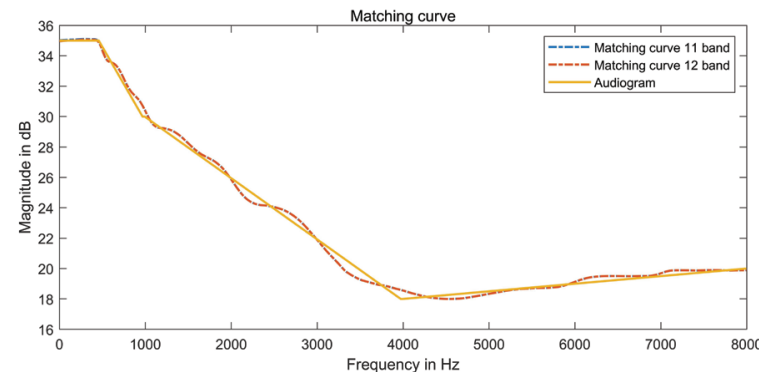

(c)

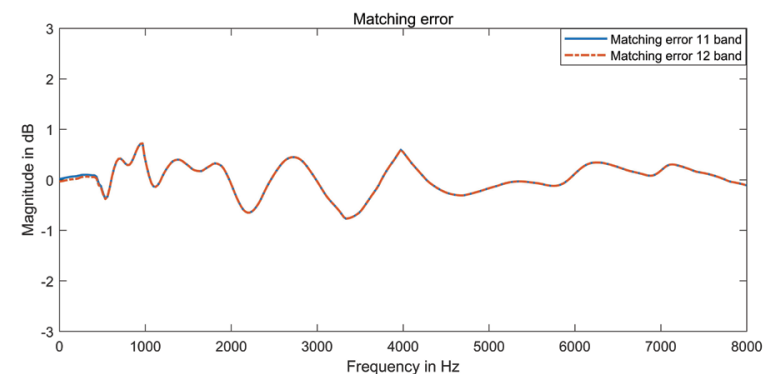

(d) filter bank is satisfactory compared to all the reported approaches.

The efficiency of the proposed method lies in the following aspects

(i) Design of the 11 bands in the filter bank is carried out using only 2 Prototype Filters, which is a reasonably low multiplier per band among the FRM methods re-

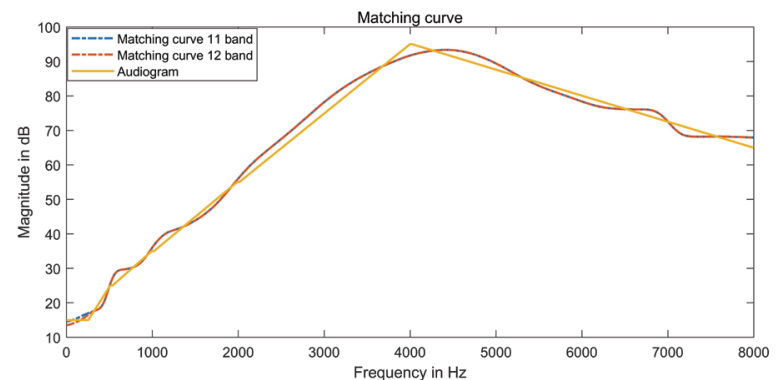

(e)

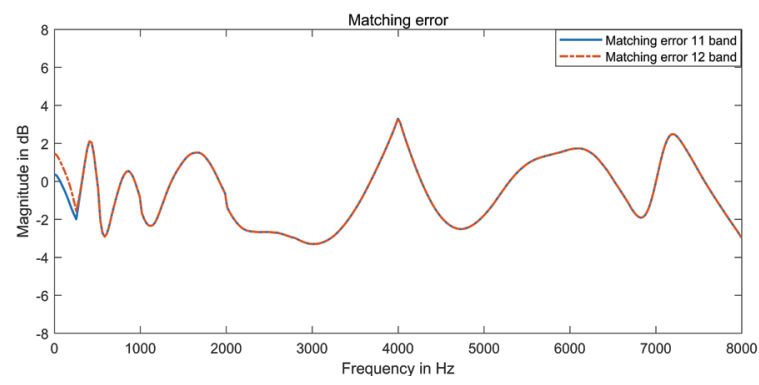

(f)

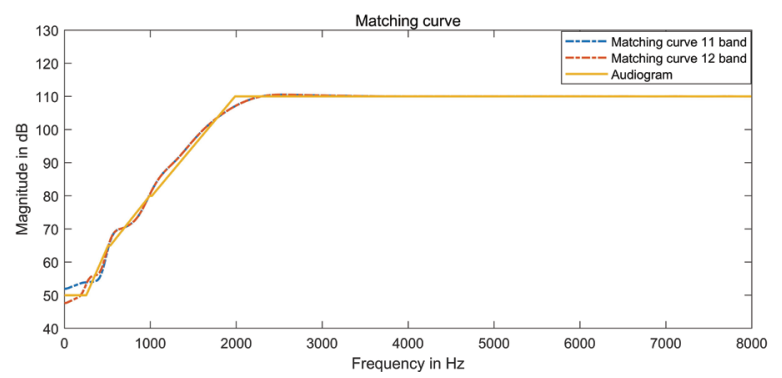

(g)

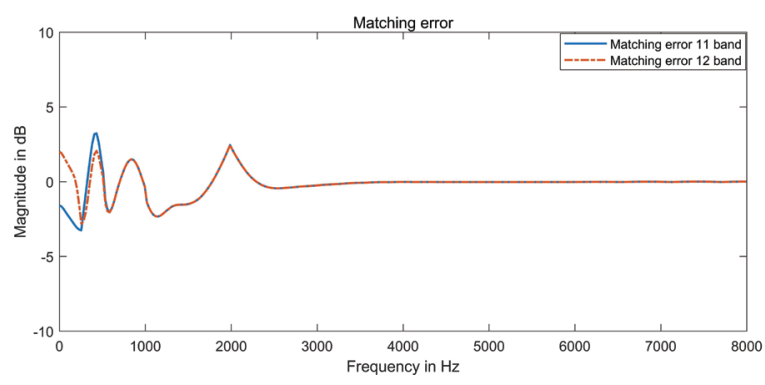

(h)

Figure 8: Matching Curves and Matching error of different Audiograms (a) \& (b) Type 1 (c) \& (d) Type 2 (e) \& (f) Type 3 (g) \& (h) Type 4 
ported in the literature. (ii) Only 19 multipliers and 38 adders are required to implement the 11 bands, which makes the proposed structure the computationally efficient than other approaches. (iii) Reasonably better audiogram matching performance especially for Type 1 and Type 2 Audiograms without optimization is achieved. (iv) Acceptable delay performance in all the sampling frequencies, making it suitable for both OHAF and CHAF.

\section{Further study on the proposed work may focus on}

(i) Reducing the transition width of filter responses using suitable methods so that sharp prototype filters can be realized at lower order and the number of multipliers can be further reduced (ii) Efficient implementation of the FIR filter structure which uses multiplier less design approaches, coefficient sharing techniques, and other suitable delay reduction techniques (iii) Low power and area efficient VLSI design strategies catering to the need of filter bank implementations suitable for HAs. (iv) Analysis of easy optimization strategies that can be introduced into the software accompanying the HAs for better audiogram matching.

\section{Conclusion}

A computationally efficient 11 band non-uniform filter bank structure suitable for the design of low or moderately sloping SNHL audiograms is proposed. The use of only two prototype filters to implement the 11 subbands makes it suitable for low-cost implementations of filter banks. The FRM method is adopted for the design of the filter bank. In this method, sharp sub-bands are realized using interpolation and masking strategies, makes it suitable for real-time implementations. This technique has a negligible matching error and acceptable group delay. The frequency band splitting is carried out by considering the non-uniform characteristics of the human ear, which has high resolution at lower frequencies. The total number of multipliers required to implement the entire filter bank is 19. This is around 70-90\% multiplier saving compared to non FRM methods and around $40-80 \%$ multiplier saving compared to FRM methods. Since the filter bank is implemented using a smaller number of multipliers, it can lead to an area and power-efficient implementation of the HAs.

\section{Conflict of Interest}

We have no conflict of interest to declare.

\section{References}

1. R. Crochiere and L.Rabiner, Multirate digital signal processing. Englewood Cliffs: Prentice-Hall, 1983.

2. P. Vaidyanathan, Multirate systems and filter banks. Englewood Cliffs: Prentice Hall, 1993.

3. Y. Neuvo, Dong Cheng-Yu and S. Mitra, "Interpolated finite impulse response filters," in IEEE Transactions on Acoustics, Speech, and Signal Processing, vol. 32, no. 3, pp. 563-570, June 1984. https://doi.org/10.1109/TASSP.1984.1164348

4. Yong Lim, "Frequency-response masking approach for the synthesis of sharp linear phase digital filters," in IEEE Transactions on Circuits and Systems, vol. 33, no. 4, pp. 357-364, April 1986. https://doi.org/10.1109/TCS.1986.1085930

5. Y. Lim, "A digital filter bank for digital audio systems," in IEEE Transactions on Circuits and Systems, vol. 33, no. 8, pp. 848-849, August 1986. https://doi.org/10.1109/TCS.1986.1085988

6. T. Lunner and J. Hellgren, "A digital filterbank hearing aid-design, implementation and evaluation," [Proceedings] ICASSP 91: 1991 International Conference on Acoustics, Speech, and Signal Processing, Toronto, Ontario, Canada, 1991, pp. 36613664 vol.5

https://doi.org/10.1109/ICASSP.1991.151068

7. Ying Wei and Yong Lian, "A computationally efficient non-uniform digital FIR filter bank for hearing aid," IEEE International Workshop on Biomedical Circuits and Systems, 2004., Singapore, 2004, pp. S1/3/INV-S1/17.

https://doi.org/10.1109/BIOCAS.2004.1454116

8. Yong Lian and Ying Wei, "A computationally efficient nonuniform FIR digital filter bank for hearing aids," in IEEE Transactions on Circuits and Systems I: Regular Papers, vol. 52, no. 12, pp. 2754-2762, Dec. 2005. https://doi.org/10.1109/TCSI.2005.857871

9. Y. Wei and Y. Lian, "A 16-band nonuniform FIR digital filter bank for hearing aid," 2006 IEEE Biomedical Circuits and Systems Conference, London, 2006, pp. 186-189.

https://doi.org/10.1109/BIOCAS.2006.4600339

10. Y. Wei, T. Ma, B. K. Ho and Y. Lian, "The Design of Low-Power 16-Band Nonuniform Filter Bank for Hearing Aids," in IEEE Transactions on Biomedical Circuits and Systems, vol. 13, no. 1, pp. 112-123, Feb. 2019.

https://doi.org/10.1109/TBCAS.2018.2888860

11. Y. Wei and D. Liu, "A design of digital FIR filter banks with adjustable subband distribution for hearing aids," 2011 8th International Conference on Information, Communications \& Signal Processing, Singapore, 2011, pp. 1-5. 
12. Y. Wei and D. Liu, "A Reconfigurable Digital Filterbank for Hearing-Aid Systems With a Variety of Sound Wave Decomposition Plans," in IEEE Transactions on Biomedical Engineering, vol. 60, no. 6, pp. 1628-1635, June 2013. https://doi.org/10.1109/ICICS.2011.6173544

13. Y. Wei and Y. Wang, "Design of Low Complexity Adjustable Filter Bank for Personalized Hearing Aid Solutions," in IEEE/ACM Transactions on Audio, Speech, and Language Processing, vol. 23, no. 5, pp. 923-931, May 2015. https://doi.org/10.1109/TASLP.2015.2409774

14. Y. Kuo, T. Lin, Y. Li and C. Liu, "Design and Implementation of Low-Power ANSI S1.11 Filter Bank for Digital Hearing Aids," in IEEE Transactions on Circuits and Systems I: Regular Papers, vol. 57, no. 7, pp. 1684-1696, July 2010. https://doi.org/10.1109/TCSI.2009.2033539

15. C. Liu, K. Chang, M. Chuang and C. Lin, "10-ms 18Band Quasi-ANSI S1.11 1/3-Octave Filter Bank for Digital Hearing Aids," in IEEE Transactions on Circuits and Systems I: Regular Papers, vol. 60, no. 3, pp. 638-649, March 2013.

https://doi.org/10.1109/TCSI.2012.2209731

16. S. Lai, C. Liu, L. Wang, S. Chen and K. Chen, "11.25-ms-Group-Delay and Low-Complexity Algorithm Design of 18-Band Quasi-ANSI S1.11 1/3 Octave Digital Filterbank for Hearing Aids," in IEEE Transactions on Circuits and Systems I: Regular Papers, vol. 62, no. 6, pp. 1572-1581, June 2015. https://doi.org/10.1109/TCSI.2015.2411795

17. C. Yang, C. Liu and S. Jou, "A Systematic ANSI S1.11 Filter Bank Specification Relaxation and Its Efficient Multirate Architecture for Hearing-Aid Systems," in IEEE/ACM Transactions on Audio, Speech, and Language Processing, vol. 24, no. 8, pp. 1380-1392, Aug. 2016. https://doi.org/10.1109/TASLP.2016.2556422

18. Shaeen Kalathil, Elizabeth Elias, Efficient design of non-uniform cosine modulated filter banks for digital hearing aids, AEU - International Journal of Electronics and Communications,Volume 69, Issue 9, 2015, Pages 1314-1320. https://doi.org/10.1016/j.aeue.2015.05.015

19. Nisha Haridas, Elizabeth Elias, Efficient variable bandwidth filters for digital hearing aid using Farrow structure, Journal of Advanced Research, Volume 7, Issue 2, 2016, Pages 255-262. https://doi.org/10.1016/j.jare.2015.06.002

20. Nisha Haridas, Elizabeth Elias, Design of reconfigurable low-complexity digital hearing aid using Farrow structure based variable bandwidth filters, Journal of Applied Research and Technology, Volume 14, Issue 2, 2016, Pages 154-165. https://doi.org/10.1016/j.jart.2016.03.005
21. Stone, Michael A., et al. "Tolerable Hearing Aid Delays. V. Estimation of Limits for Open Canal Fittings." Ear and Hearing, vol. 29, no. 4, 2008, pp. 601-617. https://doi.org/10.1097/AUD.0b013e3181734ef2

22. Stone M.A. \& Moore B.C.J. 2002. Tolerable hearing aid delays. II. Estimation of limits imposed during speech production. Ear Hear , 23, 325 - 338. Stone M.A. \& Moore B.C.J. 2003.

https://doi.org/10.1097/00003446-200208000-00008

23. Tolerable hearing aid delays. III. Effects on speech production and perception of across-frequency variation in delay. Ear Hear , 24, 175 - 183. Stone M.A. \& Moore B.C.J. 2005.

24. Tolerable hearing-aid delays IV. Effects on subjective disturbance during speech production by hearing-impaired subjects. Ear Hear , 26, 225 235.

https://doi.org/10.1097/01.AUD.0000058106.68049.9C

25. Joshua Alexander, "Hearing Aid Delay and Current Drain in Modern Digital Devices", Canadian Audiologist, Vol. 6 , Issue 6, 2019. http://canadianaudiologist.ca/hearing-aid-delay-feature/

26. Høydal EH. (2017) A new own voice processing system for optimizing communication. Hearing Review. 24(11):20-22. https://www.hearingreview.com/practicebuilding/marketing/ new-voice-processing-system-optimizing-communication

27. Goehring, Tobias, et al. "Tolerable Delay for Speech Production and Perception: Effects of Hearing Ability and Experience with Hearing Aids." International Journal of Audiology, vol. 57, no. 1, 2017, pp. 61-68. https://doi.org/10.1080/14992027.2017.1367848

28. McGrath $\mathrm{M}$ and Summerfield Q. Intermodal timing relations and audiovisual speech recognition by normal-hearing adults. J Acoust Soc Amer 1985;77:678-85.

https://doi.org/10.1121/1.392336

29. Wong, Lena $\mathrm{L} N$ et al. "Hearing aid satisfaction: what does research from the past 20 years say?." Trends in amplification vol. 7,4 (2003): 117-61. https://doi.org/10.1177/108471380300700402

30. Cox, Robyn M et al. "Impact of Hearing Aid Technology on Outcomes in Daily Life I: The Patients' Perspective." Ear and hearing vol. 37,4 (2016): https://doi.org/10.1097/AUD.0000000000000277

31. Chien W, Lin F. Prevalence of hearing aid use among older adults in the United States. Arch Intern Med. 2012;172(3):292-293 https://doi.org/10.1001/archinternmed.2011.1408

32. Aahz, H., \& Moore, B.C.J. (2007). The value of routine real ear measurement of the gain of digital hearing aids. Journal of the American Academy of Audiology, 18, 653-664. https://doi.org/10.3766/jaaa.18.8.3 
33. Woods, W.S., Van Tasell, D.J., Rickert, M.E., \& Trine, T.D. (2006). SII and fit-to-target analysis of compression system performance as a function of number of compression channels. International Journal of Audiology, 45, 630-644.

https://doi.org/10.1080/14992020600937188

34. Kates, J.M. (2010). Understanding compression: Modeling the effects of dynamic-range compression in hearing aids. International Journal of Audiology, 49, 395-409.

https://doi.org/10.3109/14992020903426256

35. Dakshina G. De Silva, Nidhi Thakur \& Mengzhi Xie (2013) A hedonic price analysis of hearing aid technology, Applied Economics, 45:16, 23152323, https://doi.org/10.1080/00036846.2012.663473

36. Penteado, Silvio Pires, and Ricardo Ferreira Bento. "Performance analysis of ten brands of batteries for hearing aids." International archives of otorhinolaryngology vol. 17,3 (2013): 291-304. https://doi.org/10.7162/S1809-977720130003000010

37. Mccreery, Ryan W., et al. "Characteristics of Hearing Aid Fittings in Infants and Young Children." Ear and Hearing, vol. 34, no. 6, 2013, pp. 701-710., https://doi.org/10.1097/AUD.0b013e31828f1033

38. http://www.earinfo.com/how-to-read-a-hearingaid-test/common-audiograms

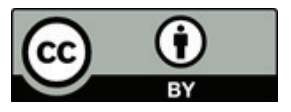

Copyright $\odot 2020$ by the Authors. This is an open access article distributed under the Creative Commons Attribution (CC BY) License (https://creativecommons.org/licenses/by/4.0/), which permits unrestricted use, distribution, and reproduction in any medium, provided the original work is properly cited.

Arrived: 21. 02. 2020

Accepted: 26. 08. 2020 